\title{
Description of Francisella hispaniensis sp. nov., isolated from human blood, reclassification of Francisella novicida (Larson et al. 1955) Olsufiev et al. 1959 as Francisella tularensis subsp. novicida comb. nov. and emended description of the genus Francisella
}

\author{
Correspondence \\ Hans-Jürgen Busse \\ hans-juergen.busse@vetmeduni. \\ ac.at
}

Birgit Huber, ${ }^{1}$ Raquel Escudero, ${ }^{2}$ Hans-Jürgen Busse, ${ }^{1}$ Erik Seibold, ${ }^{3}$ Holger C. Scholz, ${ }^{3}$ Pedro Anda, ${ }^{2}$ Peter Kämpfer ${ }^{4}$ and Wolf D. Splettstoesser ${ }^{3}$

\footnotetext{
${ }^{1}$ Institut für Bakteriologie, Mykologie und Hygiene, Veterinärmedizinische Universität, Veterinärplatz 1, A-1210 Wien, Austria

${ }^{2}$ Laboratorio de Espiroquetas y Patógenos Especiales, Centro Nacional de Microbiología Instituto de Salud Carlos III, Madrid, Spain

${ }^{3}$ Bundeswehr Institute of Microbiology, D-80937 Munich, Germany

${ }^{4}$ Institut für Angewandte Mikrobiologie, Justus-Liebig-Universität Giessen, D-35392 Giessen, Germany
}

Strain FhSp $1^{\top}$, isolated from human blood in Spain in 2003, was studied for its taxonomic allocation. By $16 \mathrm{~S}$ rRNA and recA gene sequencing, the strain was shown to belong to the genus Francisella. In the $16 \mathrm{~S}$ rRNA gene sequence, Francisella sp. FhSp1 ${ }^{\top}$ shared similarity of more than $99 \%$ with strains of Francisella tularensis subspecies and Francisella novicida $\mathrm{U}_{11}{ }^{\top}, 98 \%$ with Francisella piscicida GM2212 ${ }^{\top}$ and $98.4 \%$ with Francisella philomiragia ATCC $25015^{\top}$. In the recA gene sequence, Francisella sp. FhSp $1^{\top}$ exhibited $91.6-91.7 \%$ similarity to strains of $F$. tularensis subspecies, $91.2 \%$ to F. novicida $U 112^{\top}$ and $84 \%$ to F. philomiragia ATCC 25017 . The genus affiliation was supported by a quinone system typical of Francisella (Q-8 as the major component), a complex polar lipid profile similar to that of $F$. tularensis with the major components diphosphatidylglycerol, phosphatidylethanolamine, phosphatidylcholine and an unknown aminophospholipid (APL4) and a fatty acid profile consisting mainly of $\mathrm{C}_{10: 0}(17.2 \%), \mathrm{C}_{14: 0}$ (11.2\%), $\mathrm{C}_{16: 0}(13.1 \%), \mathrm{C}_{18: 0} 3-\mathrm{OH}(14.2 \%)$ and $\mathrm{C}_{18: 1} \omega 9 \mathrm{c}(7.1 \%)$. DNA-DNA hybridization, which showed unambiguously that $\mathrm{FhSp} 1^{\top}$ represents a novel species, and the results of biochemical tests allowed genotypic and phenotypic differentiation of the isolate from all hithertodescribed Francisella species. A multiplex PCR developed in the course of this study discriminated $\mathrm{FhSp} 1^{\top}$ from representatives of all other Francisella species and subspecies, clades A.I and A.II of $F$. tularensis subsp. tularensis and $F$. tularensis subsp. holarctica biovar japonica and also between these representatives of the genus. Therefore, we propose the name Francisella hispaniensis sp. nov., with the type strain $\mathrm{FhSp} 1^{\top}\left(=\mathrm{FnSp}^{\top}{ }^{\top}=\mathrm{FSC} 454^{\top}=\mathrm{F} 62^{\top}=\mathrm{DSM} 22475^{\top}=\mathrm{CCUG}^{\top} 8020^{\top}\right)$. Furthermore, we formally propose the transfer of the species Francisella novicida to the species Francisella tularensis as Francisella tularensis subsp. novicida comb. nov. (type strain ATCC $15482^{\top}$ $=$ CCUG $33449^{\top}=$ CIP $56 \cdot 12^{\top}$ ). We also present an emended description of the genus Francisella.
Francisella tularensis is a facultatively intracellular bacterium, and all its subspecies cause the zoonotic disease tularaemia in humans and animals. Francisella philomiragia and Francisella novicida strains, although generally less virulent than strains of F. tularensis, may cause a tularaemia-like disease in immunocompromised patients (Hollis et al., 1989). 
The genus Francisella, together with Wolbachia persica, Fangia hongkongensis and Caedibacter taeniospiralis, represents one of, if not the deepest branch in the class Gammaproteobacteria (Forsman et al., 1994; Lau et al., 2007; Gao et al., 2009). At the time of writing, the genus Francisella comprises four recognized species, F. tularensis, with the three subspecies $F$. tularensis subsp. tularensis, $F$. tularensis subsp. holarctica and $F$. tularensis subsp. mediasiatica, $F$. novicida, $F$. philomiragia and $F$. noatunensis (formerly F. philomiragia subsp. noatunensis), with the two subspecies $F$. noatunensis subsp. noatunensis and $F$. noatunensis subsp. orientalis (McCoy \& Chapin, 1912; Larson et al., 1955; Olsufiev et al., 1959; Olsufjev \& Meshcheryakova, 1983; Hollis et al., 1989; Ottem et al., 2009; Mikalsen et al., 2007). A fifth species, Francisella piscicida (Ottem et al., 2007), was proposed to represent a later heterotypic synonym of $F$. noatunensis subsp. noatunensis (Ottem et al., 2009) based on high degrees of sequence similarities in certain housekeeping genes and results from DNA-DNA hybridizations slightly below the threshold (70\% reassociation) for species delineation. However, the reliability of these taxonomic rearrangements cannot be considered to be certain and, hence, we use the name $F$. piscicida in this contribution.

In several publications, including the chapter on Francisella in the second edition of Bergey's Manual of Systematic Bacteriology (Sjöstedt, 2005), F. novicida is named Francisella tularensis subsp. novicida (Sjöstedt, 2005), but this name is not formally correct; although Sjöstedt (2005) proposed the transfer of this species to $F$. tularensis as the subspecies ' $F$. tularensis subsp. novicida', this name has never been validly published.

Strain FhSp1 $1^{\mathrm{T}}$ was presumptively identified as a strain of $F$. novicida (Escudero et al., 2003). However, recent analyses of five housekeeping genes and two genes encoding membrane proteins (Nübel et al., 2006; Escudero et al., 2010) as well as genomic fingerprinting using RAPD-PCR carried out in the course of our study (results not shown) revealed a clearly distant position of this strain from recognized Francisella species and subspecies. This uncertain taxonomic affiliation was further affirmed by the results of DNA typing methods employing 38 canonical insertion-deletion markers, in which strain $\mathrm{FhSp}^{\mathrm{T}}$ failed in amplification of seven tested loci (Larsson et al., 2007). Escudero et al. (2008) named strain $\mathrm{FhSp} 1^{\mathrm{T}}$ an unusual $F$. tularensis strain. Here we report the classification of $\mathrm{FhSp}^{\mathrm{T}}$ as a member of a novel species of Francisella, applying biochemical, physiological, chemotaxonomic and genetic characterization. Furthermore, we formally propose to transfer the species $F$. novicida to the species $F$. tularensis as Francisella tularensis subsp. novicida comb. nov.

FhSp1 ${ }^{\mathrm{T}}$ showed distinct, convex, pale-white to grey colonies that reached maximum size $(3-4 \mathrm{~mm}$ diameter) in $48 \mathrm{~h}$ on cysteine heart agar (HCA; BD) at $37^{\circ} \mathrm{C}$. Cysteine is not required for growth but enhances it. FhSp1 $1^{\mathrm{T}}$ could also be grown on Columbia blood agar, whereas no growth occurred on MacConkey agar plates. Cell morphology was observed under an Axiostar microscope (Zeiss) at $\times 1000$, with cells grown for 2 days at $37^{\circ} \mathrm{C}$ on HCA. The pleomorphic and coccoid rods of $\mathrm{FhSp}^{\mathrm{T}}$ stained faintly Gram-negative.

Amplification and sequencing of the 16S rRNA-encoding gene and recA were carried out as reported previously (Scholz et al., 2006) using the primers listed in Table 1 (16S rRNA gene: 27f, 1492r, 341f, 518r, 926f; recA: recA_tul_f, recA_tul_r). Amplification of recA consisted of an initial denaturation step at $94{ }^{\circ} \mathrm{C}$ for $5 \mathrm{~min}$ and 30 cycles of denaturation at $94{ }^{\circ} \mathrm{C}$ for $30 \mathrm{~s}$, annealing at $60{ }^{\circ} \mathrm{C}$ for $30 \mathrm{~s}$ and elongation at $72{ }^{\circ} \mathrm{C}$ for $30 \mathrm{~s}$ and a final elongation step at $72{ }^{\circ} \mathrm{C}$ for $60 \mathrm{~s}$. Primers recA_tul_f and recA_tul_r were constructed based on accessible genomic sequences of certain francisellae. 16S rRNA gene $(1471 \mathrm{bp})$ and recA (965 bp) sequences of $\mathrm{FhSp}^{\mathrm{T}}$ were compared to entries in the EMBL database using the FASTA33 search tool (Pearson \& Lipman, 1988). Strain FhSp $1^{\mathrm{T}}$ showed $99.7 \%$ 16S rRNA gene sequence similarity to $F$. novicida $\mathrm{U}_{112^{\mathrm{T}}}$ and $F$. tularensis subsp. tularensis SCHU S4 and strain FSC198, 99.5-99.6\% to other F. tularensis subspecies, 98.2-98.4\% to strains of $F$. philomiragia, including the type strain ATCC $25015^{\mathrm{T}}$, and $98.0 \%$ to F. piscicida $\mathrm{GM} 2212^{\mathrm{T}}$. The recA gene sequence of $\mathrm{FhSp}^{\mathrm{T}}$ shared $91.2-91.7 \%$ with the corresponding sequences of members of different Francisella subspecies, including F. novicida $\mathrm{U} 112^{\mathrm{T}}$, and $84 \%$ with that of F. philomiragia ATCC 25017 in 941 overlapping positions. recA sequences of recognized Francisella subspecies shared 99.9-100\% similarity with each other and 98.9$99.0 \%$ with that of F. novicida $\mathrm{U} 112^{\mathrm{T}}$. These data indicate a close relatedness of $F$. novicida to $F$. tularensis and a quite distant position of $\mathrm{FhSp}^{\mathrm{T}}$ from recognized Francisella species. Subsequent analysis of the $r e c A$ gene was performed using the software package MEGA version 4.0 (Tamura et al., 2007) after multiple alignment of sequences by CLUSTAL_X (Thompson et al., 1997). Distance options were according to the maximum composite likelihood model and clustering with the neighbour-joining method was performed by using bootstrap values based on 2000 replications. A recAbased tree is shown in Fig. 1. In further analyses, the relatedness of $\mathrm{FhSp1}^{\mathrm{T}}$ and $F$. novicida suggested by sequence similarities was confirmed.

For fatty acid, polar lipid and quinone analysis, cells were grown on $\mathrm{HCA}$ at $37{ }^{\circ} \mathrm{C}$ with $5 \% \mathrm{CO}_{2}$ for $48 \mathrm{~h}$, except $F$. piscicida DSM $18777^{\mathrm{T}}$, which was kept at $20{ }^{\circ} \mathrm{C}$ under ambient atmosphere, suspended in PBS, heat-killed and then lyophilized. Fatty acid methyl esters were prepared as described by Kämpfer \& Kroppenstedt (1996).

The fatty acid profile of $\mathrm{FhSp}^{\mathrm{T}}$ consisted of $\mathrm{C}_{10: 0}$ (17.2\%), $\mathrm{C}_{18: 0} 3-\mathrm{OH}(14.2 \%), \mathrm{C}_{16: 0}(13.1 \%), \mathrm{C}_{14: 0}$ (11.2\%), $\mathrm{C}_{18: 1} \omega 9 c(7.1 \%), \mathrm{C}_{24: 1}(5.0 \%), \mathrm{C}_{18: 0}(3.8 \%)$, $\mathrm{C}_{16: 0} 3-\mathrm{OH}(2.8 \%), \mathrm{C}_{10: 0} 2-\mathrm{OH}(2.7 \%), \mathrm{C}_{22: 0}(2.5 \%)$, $\mathrm{C}_{24: 0}(2.5 \%), \mathrm{C}_{20: 0}(1.7 \%)$, iso- $\mathrm{C}_{15: 0} 2-\mathrm{OH}$ and/or $\mathrm{C}_{16: 1} \omega 7 c \quad(1.4 \%), \quad$ anteiso- $\mathrm{C}_{15: 0} \quad(1.6 \%), \quad$ iso- $\mathrm{C}_{15: 0}$ $(1.1 \%), \mathrm{C}_{12: 0}(0.9 \%), \mathrm{C}_{20: 2} \omega 6,9 c(0.8 \%), \mathrm{C}_{17: 0} 3-\mathrm{OH}$ 
Table 1. Oligonucleotide primers used in this study and expected amplicon sizes when used in multiplex PCR

Primers were designed in this study unless indicated otherwise.

\begin{tabular}{|c|c|c|c|}
\hline Primer & Sequence $\left(5^{\prime}-3^{\prime}\right)$ & Reference $^{\star}$ & Amplicon size (bp) \\
\hline \multicolumn{4}{|l|}{ RAPD-PCR } \\
\hline RAPD1a & GTGCCGACGG & - & - \\
\hline RAPD2a & ATAGCCGACG & - & - \\
\hline RAPD2b & ATAGCCGACGC & - & - \\
\hline RAPD3a & TCTGACCACC & - & - \\
\hline RAPD4 & CAGGCTTCCC & - & - \\
\hline RAPD5 & CGGCAACGGG & - & - \\
\hline RAPD6 & GACTGCGCAC & - & - \\
\hline RAPD7 & GCGTCAGGAG & - & - \\
\hline RAPD9 & AACAGGGCGG & - & - \\
\hline RAPD10 & GGACGCGGTGC & - & - \\
\hline RAPD16 & GTTCGTGCGGT & - & - \\
\hline RAPD17 & CGTTTCAATG & - & - \\
\hline RAPD18 & GTTACATCAGTGC & - & - \\
\hline RAPD19 & TCAACAAGGTG & - & - \\
\hline RAPD20 & AAACATTATCTGC & - & - \\
\hline RAPD21 & CAACCAGCTATAG & - & - \\
\hline RAPD22 & CTTAAAAAGGTT & - & - \\
\hline RAPD23 & AAGTTTGTTTGC & - & - \\
\hline RAPD24 & CAAAGTTTGTTTGC & - & - \\
\hline RAPD27 & AGTTTAGCTGG & - & - \\
\hline RAPD28 & TTGCTGGGG & - & - \\
\hline RD6_f & TGACCTGAGCCAGAGGTTAC & 3 & 369 \\
\hline RD6_r & ACTTGCCAGCCTAATAATTAC & 3 & \\
\hline F_nov_f & GCCATATAAAGGCAAAAGCTCCACTTC & - & 1395 \\
\hline F_nov_r & GAGGGGATATGGCAATCATCTAGAGC & - & \\
\hline F_med_f & GTCTTTGGTGGTCTTACGCCAATG & - & 1132 \\
\hline F_med_r & GCTGGAATTACACTCTCTCTTAAATCCC & - & \\
\hline F_philo_f & CGCACCCCAGTCTTTGCGATAG & - & 962 \\
\hline F_philo_r & CGCTAAATAATTCTCTTCGTAGCGATTG & - & \\
\hline F_pisc_f & GCGGTCTATCCTGTTGTCGAGAAG & - & 172 \\
\hline F_pisc_r & TTGCTTGAAATATTGGAGAAGAAATGG & - & \\
\hline F_62_f & GTTGATCGGCGATAGTACTTCATCT & - & 492 \\
\hline F_62_r & CCAAAGATCACAAAGGCATTACCTAAG & - & \\
\hline \multicolumn{4}{|c|}{$\begin{array}{l}\text { Amplification and sequencing } \\
\operatorname{rec} A\end{array}$} \\
\hline recA_tul_f & CGCTAGAATCAGCCTTATCAC & - & 965 \\
\hline recA_tul_r & TAAGCTCATCTTGAGTAACTGC & - & \\
\hline \multicolumn{4}{|c|}{ 16S rRNA gene } \\
\hline $27 f$ & GCCCATTTGAGGGGGATACC & 2 & 1474 \\
\hline $1492 \mathrm{r}$ & GGACTAAGAGTACCTTTTTGAGT & 2 & \\
\hline
\end{tabular}


Table 1. cont.

\begin{tabular}{|clcc|}
\hline Primer & Sequence $\left(\mathbf{5}^{\prime} \mathbf{- 3}^{\prime}\right)$ & Reference & Amplicon size $(\mathbf{b p})$ \\
\hline $341 \mathrm{f}$ & CCTACGGGAGGCAGCAG & 4 & - (Sequencing primer) \\
$518 \mathrm{r}$ & ATTACCGCGGCTGCTGG & 4 & - (Sequencing primer) \\
$926 \mathrm{f}$ & AAACTYAAAKGAATTGACGG & 2 & $-($ Sequencing primer) \\
\hline
\end{tabular}

${ }^{\star}$ 1, Broekhuijsen et al. (2003); 2, Lane (1991); 3, Molins-Schneekloth et al. (2007); 4, Muyzer et al. (1993).

$(0.7 \%)$, anteiso- $\mathrm{C}_{17: 1} \omega 9 c(0.6 \%), \mathrm{C}_{13: 1}$ at $12-13(0.5 \%)$, anteiso- $\mathrm{C}_{17: 0}(0.4 \%), \mathrm{C}_{9: 0}(0.1 \%)$ and an unidentified acid with an equivalent chain-length of 14.969. This fatty acid profile shares the majority of characteristics reported for different $F$. tularensis and $F$. novicida strains (Jantzen et al., 1979; Hollis et al., 1989), including relatively large amounts of $\mathrm{C}_{10: 0}, \mathrm{C}_{14: 0}, \mathrm{C}_{16: 0}, \mathrm{C}_{24: 1}$ and the long-chain hydroxy acid $\mathrm{C}_{18: 0} 3-\mathrm{OH}$ and presence of significant amounts of $\mathrm{C}_{10: 0} 2-\mathrm{OH}, \mathrm{C}_{16: 0} 3-\mathrm{OH}, \mathrm{C}_{20: 0}, \mathrm{C}_{22: 0}$ and $\mathrm{C}_{24: 0}$. A fatty acid profile containing these components is unique among bacteria and, hence, it supports the assignment of $\mathrm{FhSp}^{\mathrm{T}}$ to the genus Francisella.

Quinones were extracted and analysed by HPLC as described by Tindall (1990a) and Altenburger et al. (1996). The HPLC was equipped as described by Stolz et al. (2007). Strain FhSp1 $1^{\mathrm{T}}$ exhibited a quinone system with the major compound ubiquinone Q-8 (98\%) and traces of Q-9 (2\%). The quinone system supports the affiliation of strain FhSp $1^{\mathrm{T}}$ to the genus Francisella; several strains of the genus analysed for this trait also showed a quinone system with the major ubiquinone Q-8 (Hollis et al., 1989). Our analysis of the quinone systems of strain $\mathrm{FhSp}^{\mathrm{T}}, F$. tularensis subsp. holarctica strains F76 and ATCC 29684, F. tularensis subsp. mediasiatica F65, F. tularensis subsp. tularensis strains ATCC $6223^{\mathrm{T}}$ and SCHU S4, F. tularensis subsp. novicida ATCC $15482^{\mathrm{T}}, F$. philomiragia ATCC $25015^{\mathrm{T}}$ and F. piscicida DSM $18777^{\mathrm{T}}$ showed similar results. The main quinone was ubiquinone Q-8 (95$100 \%$ ), and minor amounts of ubiquinone Q-9 were also detected.

Polar lipids were extracted and analysed by two-dimensional TLC after Tindall (1990b). The polar lipid profile of strain $\mathrm{FhSp}^{\mathrm{T}}$ was almost identical to that of F. tularensis subsp. tularensis ATCC $6223^{\mathrm{T}}$ (Fig. 2a), differing only by the absence of trace amounts of an unidentified aminophospholipid (APL2). The polar lipid profile of F. tularensis subsp. tularensis ATCC $6223^{\mathrm{T}}$ was composed of the major lipids phosphatidylethanolamine and diphosphatidylglycerol, moderate amounts of phosphatidylcholine and an unidentified aminophospholipid (APL4) and phospholipid (PL3) and minor to trace amounts of phosphatidylglycerol, unidentified phospholipids (PL1, PL2), an unidentified lipid with highly hydrophobic chromatographic behaviour (L) and unidentified aminophosphoglycolipids (APGL1-2), aminophospholipids (APL1-3) and an aminolipid (AL2). The polar lipid profile of $F$. novicida ATCC $15482^{\mathrm{T}}$ was indistinguishable from that of $F$. tularensis subsp. tularensis ATCC $6223^{\mathrm{T}}$ (not shown). The most striking difference in the polar lipid profile of $F$. philomiragia ATCC $25015^{\mathrm{T}}$ was the absence of aminophospholipid APL4 (Fig. 2b). Furthermore, aminophospholipid APL2 was not detectable, but minor amounts of an unidentified glycolipid (GL) and an unidentified aminolipid (AL1) were found. F. piscicida DSM $18777^{\mathrm{T}}$ exhibited a polar lipid profile most similar to that of $F$. philomiragia subsp. philomiragia ATCC $25015^{\mathrm{T}}$ but with trace amounts of APL2 and no detectable APGL2, AL1, AL2 and PL1 (not shown). These polar lipid profiles reflect quite well the close phylogenetic relationship between $\mathrm{FhSp}^{\mathrm{T}}$ and $F$. tularensis subsp. tularensis on the one hand and between $F$. philomiragia ATCC $25015^{\mathrm{T}}$ and F. piscicida DSM $18777^{\mathrm{T}}$ on the other.

Metabolic fingerprinting was done using the Biolog MicroLog system (Gram-negative identification test panel GN2 MicroPlates) according to the instructions of the manufacturer. All strains were first grown on $\mathrm{HCA}$ at $37{ }^{\circ} \mathrm{C}$

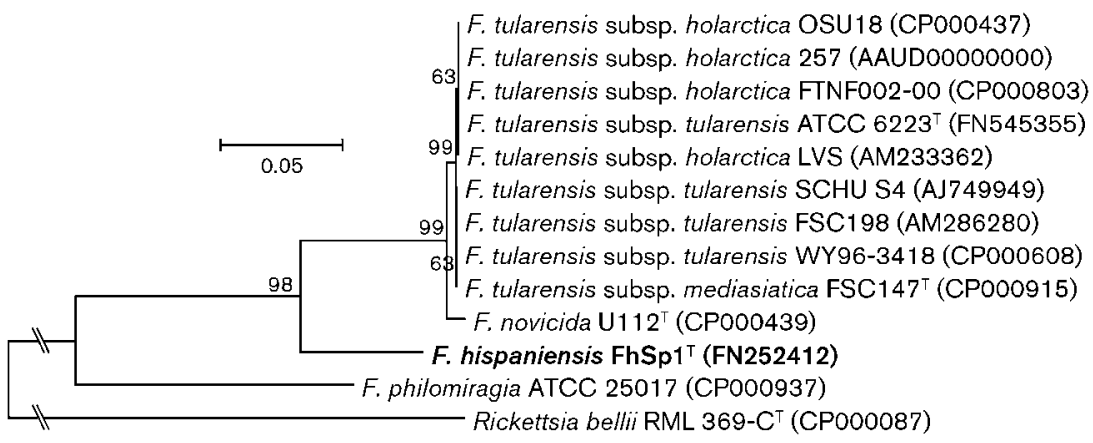

F. tularensis subsp. holarctica OSU18 (CP000437)

F. tularensis subsp. holarctica 257 (AAUD00000000)

F. tularensis subsp. holarctica FTNF002-00 (CP000803)

F. tularensis subsp. tularensis ATCC 6223 ${ }^{\top}$ (FN545355)

F. tularensis subsp. holarctica LVS (AM233362)

F. tularensis subsp. tularensis WY96-3418 (CP000608)

F. tularensis subsp. mediasiatica $\mathrm{FSC} 147^{\top}$ (CP000915)

Rickettsia bellii RML 369-C ${ }^{\top}$ (CP000087)
Fig. 1. Phylogenetic tree reconstruction with $\operatorname{rec} A$ sequences (941-944 bp) using MEGA neighbour-joining analysis. Bar, 0.05 substitutions per nucleotide position. The significance of branches is indicated by bootstrap percentages calculated for 2000 subsets. The $\operatorname{rec} A$ sequence of Rickettsia bellii RML 369- $\mathrm{C}^{\top}$ was used as an outgroup. 

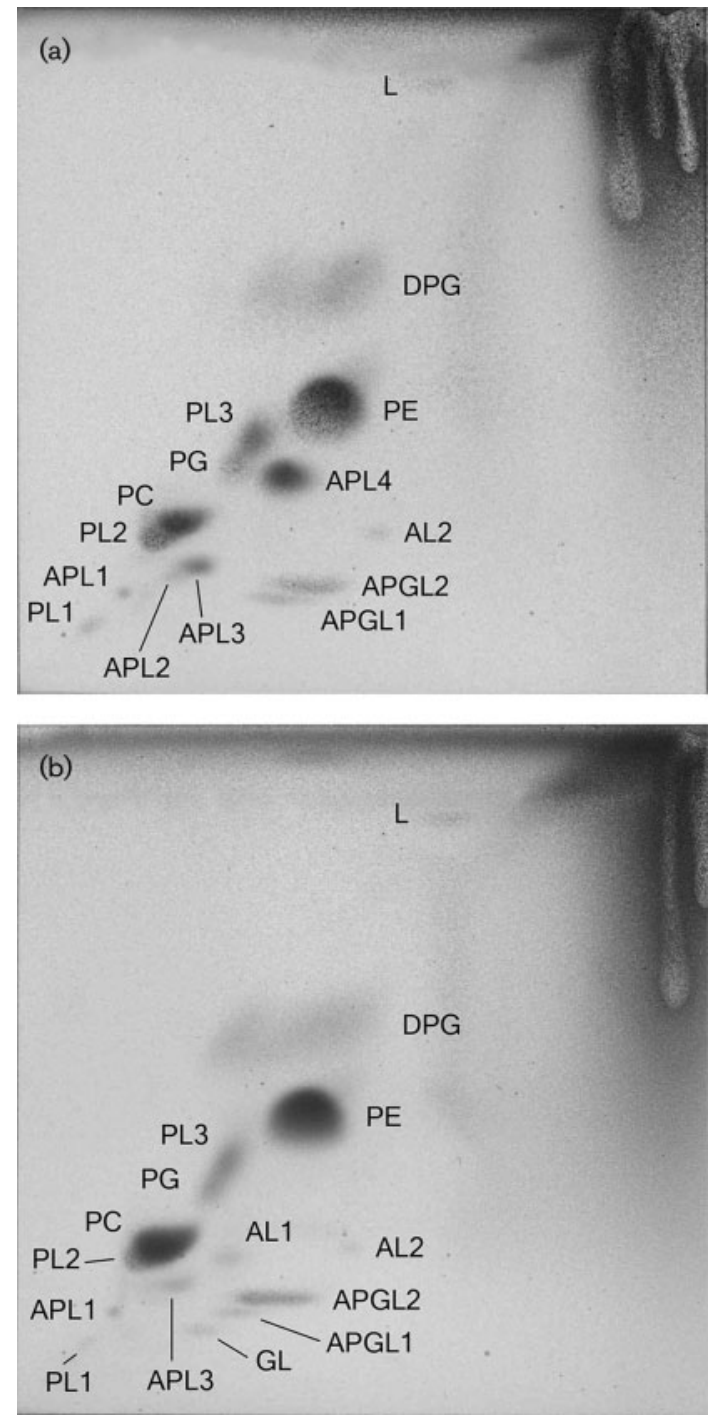

Fig. 2. Total polar lipid profiles of $F$. tularensis subsp. tularensis ATCC $6223^{\top}$ (a) and F. philomiragia ATCC $25015^{\top}$ (b) after two-dimensional TLC and detection with molybdatophosphoric acid. DPG, Diphosphatidylglycerol; PC, phosphatidylcholine; PE, phosphatidylethanolamine; PG, phosphatidylglycerol; AL12, unknown aminolipids; PL1-3, unknown phospholipids; APL1-4, unknown aminophospholipids; APGL1-2, unknown aminophosphoglycolipids; GL, unknown glycolipid; L, unknown polar lipid.

with $5 \% \mathrm{CO}_{2}$, except for F. piscicida DSM $18777^{\mathrm{T}}$, which was kept at $20{ }^{\circ} \mathrm{C}$ under ambient atmosphere. All strains were tested at least three times in independent test series. MICs of antimicrobial agents were determined by Etest (AB Biodisk; Tec-Laim) on HCA supplemented with $9 \%$ chocolatized red blood cells (CHAB). From $48 \mathrm{~h}$ cultures on $\mathrm{CHAB}$ plates, cells of strain $\mathrm{FhSp} 1^{\mathrm{T}}$ were resuspended in physiological saline to achieve a turbidity equivalent to that of a McFarland standard 0.5 and applied to the agar with the help of a sterile swab before application of Etest strips.
MICs were read after $48 \mathrm{~h}$ of incubation at $37{ }^{\circ} \mathrm{C}$ in an atmosphere with $5 \% \mathrm{CO}_{2}$. For quality assurance, each batch of plates was tested with the control strains $F$. tularensis subsp. tularensis ATCC $6223^{\mathrm{T}}$ and F. tularensis subsp. holarctica NCTC $10857^{\mathrm{T}}$.

Results of physiological and biochemical tests and susceptibility tests for antimicrobial agents are given in Table 2 or listed in the species description. Strain $\mathrm{FhSp}^{\mathrm{T}}$ differed from $F$. novicida ATCC $15482^{\mathrm{T}}$ in 13 traits and from the other type strains of recognized Francisella species and subspecies in at least 12 traits.

For environmental studies aiming at identifying potential zoonotic reservoirs of $F$. tularensis or related species as well as in epidemiology, rapid differentiation of bacterial strains belonging to the genus Francisella is mandatory. Known differences in virulence between the distinct subspecies of F. tularensis may be critical for the clinical management of tularaemia patients. Moreover, the unusual natural resistance of strains affiliated to the genus Francisella against a wide range of antibiotics necessitates the rapid identification of these strains in critically ill people. There are several lines of evidence to show that immunocompromised patients in particular are prone to infections with uncommon Francisella strains that are not detected or identified by classical microbiological methods (Kugeler et al., 2008) and which might even occur in regions that were not considered to be endemic for $F$. tularensis or related species (Leelaporn et al., 2008).

PCR-based identification of Francisella strains at the genus, species and subspecies levels has been developed by Forsman et al. (1994) on the basis of differences in the $16 \mathrm{~S}$ rRNA gene. Johansson et al. (2000) designed primers to differentiate between $F$. tularensis subsp. tularensis and F. tularensis subsp. holarctica isolates in a multiplex PCR that, however, needs further analyses in order to distinguish between these subspecies and $F$. tularensis subsp. mediasiatica and F. novicida. Broekhuijsen et al. (2003) developed a PCR based on the region of difference RD1, which was identified by a genome-wide DNA microarray analysis. This PCR allows discrimination between all three subspecies of $F$. tularensis, $F$. novicida and F. tularensis subsp. holarctica biovar japonica with one primer pair. However, it cannot discriminate between the two genotypes of $F$. tularensis subsp. tularensis, F. philomiragia, $F$. piscicida and $\mathrm{FhSp} 1^{\mathrm{T}}$ and, since the characteristic amplicon that identifies $F$. novicida is larger than $3000 \mathrm{bp}$, the PCR assay is suboptimal. In the course of this study, examinations were carried out in order to develop a comprehensive multiplex-PCR assay that allows convenient and fast discrimination between Francisella subspecies and species, including FhSp1 $1^{\mathrm{T}}$.

PCR template DNA was prepared by three cycles of freezethawing (Wieser \& Busse, 2000) from heat-inactivated biomass. In order to find genomic differences suitable for the design of specific primers, comparative genomic fingerprinting was carried out with representatives of each 
Table 2. Differential metabolic characteristics of strain FhSp $1^{\top}$ and the type strains of other francisellae

Strains: 1, FhSp1 ${ }^{\mathrm{T}}$; 2, F. novicida ATCC $15482^{\mathrm{T}}$; 3, F. philomiragia ATCC $25015^{\mathrm{T}}$; 4, F. piscicida DSM $18777^{\mathrm{T}}$; 5, F. tularensis subsp. tularensis ATCC $6223^{\mathrm{T}}$; 6, F. tularensis subsp. mediasiatica GIEM543; 7, F. tularensis subsp. holarctica GIEM503 ${ }^{\mathrm{T}}$. The tests were carried out with the Biolog GN2 MicroPlate system; tests with F. piscicida DSM $18777^{\mathrm{T}}$ were carried out with $24 \mathrm{~h}$ of incubation at $20^{\circ} \mathrm{C}$; other tests were carried out for $24 \mathrm{~h}$ at $37{ }^{\circ} \mathrm{C}$. + , Positive; -, negative; $(+)$, weakly positive. All strains were positive for oxidation of D-fructose, L-serine, L-proline, L-glutamic acid, D-mannose, pyruvic acid methyl ester and $\alpha$-D-glucose. All strains were negative for oxidation of water (control), $\alpha$-cyclodextrin, Tweens 40 and 80, $\mathrm{N}$-acetyl-D-galactosamine, adonitol, L-arabinose, D-arabitol, i-erythritol, L-fucose, gentiobiose, myo-inositol, lactose, lactulose, D-mannitol, melibiose, methyl $\beta$-D-glucoside, D-psicose, raffinose, L-rhamnose, D-sorbitol, turanose, xylitol, cis-aconitic acid, citric acid, formic acid, Dgalactonic acid lactone, D-galacturonic acid, D-gluconic acid, Dglucosaminic acid, D-glucuronic acid, $\gamma$-hydroxybutyric acid, $p$ hydroxyphenylacetic acid, itaconic acid, $\alpha$-ketovaleric acid, malonic acid, propionic acid, quinic acid, D-saccharic acid, sebacic acid, glucuronamide, L-histidine, L-leucine, L-phenylalanine, D-serine, DLcarnitine, urocanic acid, phenylethylamine, putrescine, 2-aminoethanol and 2,3-butanediol. Identification results according to Biolog were F. philomiragia for strains 1-4 and F. tularensis for strains 5-7.

\begin{tabular}{|c|c|c|c|c|c|c|c|}
\hline Test & 1 & 2 & 3 & 4 & 5 & 6 & 7 \\
\hline \multicolumn{8}{|l|}{ Activity of: } \\
\hline Catalase & $(+)$ & $(+)$ & + & + & + & + & $(+)$ \\
\hline Oxidase & + & - & + & - & - & - & - \\
\hline \multicolumn{8}{|l|}{ Oxidation of: } \\
\hline Dextrin & + & - & - & - & - & - & - \\
\hline Glycogen & + & - & - & - & - & - & - \\
\hline$N$-Acetyl-D-glucosamine & + & + & + & + & + & - & + \\
\hline Cellobiose & + & + & - & - & - & - & - \\
\hline D-Galactose & + & + & - & - & - & + & - \\
\hline Maltose & - & - & + & - & - & - & - \\
\hline Sucrose & + & + & + & - & - & - & - \\
\hline Trehalose & + & - & + & - & - & - & - \\
\hline Succinic acid monomethyl ester & + & + & + & + & - & + & + \\
\hline Acetic acid & + & - & - & - & - & - & - \\
\hline$\alpha$-Hydroxybutyric acid & + & - & + & - & - & - & - \\
\hline$\beta$-Hydroxybutyric acid & + & + & + & - & - & - & - \\
\hline$\alpha$-Ketobutyric acid & + & + & + & - & + & + & + \\
\hline$\alpha$-Ketoglutaric acid & + & - & - & - & - & - & - \\
\hline DL-Lactic acid & + & + & + & - & - & - & + \\
\hline Succinic acid & + & + & - & - & - & - & - \\
\hline Bromosuccinic acid & + & - & - & - & - & - & - \\
\hline Succinamic acid & - & - & + & - & - & - & - \\
\hline L-Alaninamide & + & + & + & + & - & - & - \\
\hline D-Alanine & + & + & + & - & - & - & - \\
\hline L-Alanine & + & + & + & + & - & + & + \\
\hline L-Alanyl glycine & + & + & + & + & - & - & - \\
\hline L-Asparagine & + & + & + & + & - & - & + \\
\hline L-Aspartic acid & + & + & + & - & - & - & + \\
\hline Glycyl L-aspartic acid & + & - & - & - & - & - & - \\
\hline Glycyl L-glutamic acid & + & + & + & - & - & - & - \\
\hline
\end{tabular}

Table 2. cont.

\begin{tabular}{|lccccccc|}
\hline Test & $\mathbf{1}$ & $\mathbf{2}$ & $\mathbf{3}$ & $\mathbf{4}$ & $\mathbf{5}$ & $\mathbf{6}$ & $\mathbf{7}$ \\
\hline Hydroxy-L-proline & + & - & - & - & - & - & - \\
L-Ornithine & + & + & - & - & - & - & - \\
L-Pyroglutamic acid & + & + & + & - & - & - & - \\
L-Threonine & + & + & + & - & - & - & + \\
$\gamma$-Aminobutyric acid & + & - & - & - & - & - & - \\
Inosine & + & + & + & - & - & - & - \\
Uridine & + & + & + & - & - & - & + \\
Thymidine & + & + & + & - & - & - & + \\
Glycerol & + & + & + & - & + & + & - \\
DL- $\alpha$-Glycerol phosphate & + & + & + & - & + & + & + \\
$\alpha$-D-Glucose 1-phosphate & + & - & + & - & - & - & - \\
D-Glucose 6-phosphate & + & - & + & - & - & - & - \\
\hline
\end{tabular}

Francisella taxon (results not shown). Primers used for RAPD-PCR fingerprinting and their sequences are listed in Table 1. Reactions were carried out in a final volume of $25 \mu$ containing $1 \times$ Green GoTaq Flexi buffer, $2 \mathrm{mM}$ $\mathrm{MgCl}_{2}, 200 \mu \mathrm{M}$ each dNTP, 0.6 U GoTaq DNA polymerase (Promega), $8 \mu \mathrm{M}$ RAPD primer and approximately 5 ng DNA. Reactions were performed using an initial 5 min denaturation step at $95{ }^{\circ} \mathrm{C}$ followed by 45 cycles of $1 \mathrm{~min}$ at $95{ }^{\circ} \mathrm{C}, 1 \mathrm{~min}$ at $32-38{ }^{\circ} \mathrm{C}$ and $2 \mathrm{~min}$ at $72{ }^{\circ} \mathrm{C}$ and a final extension step of $5 \mathrm{~min}$ at $72{ }^{\circ} \mathrm{C}$. The resolution of bands was improved by using a ramp rate of $0.3{ }^{\circ} \mathrm{C} \mathrm{s}^{-1}$. Amplification products ( $5 \mu \mathrm{l}$ each) were separated by $1.5 \%$ $(\mathrm{w} / \mathrm{v})$ agarose gel electrophoresis in $1 \times$ TAE running buffer at a constant voltage of $110 \mathrm{~V}$ for at least $90 \mathrm{~min}$. Fragments were visualized with UV light after staining with ethidium bromide. Bands of interest were excised from the gel and DNA was eluted with the QIAquick gel extraction kit according to the instructions of the manufacturer (Qiagen). PCR products were cloned using the Promega pGEM-T Easy vector system and Escherichia coli strain DH10B according to the manufacturer's manual. Plasmid insert sequences (sequencing was done at VBC-genomics, Vienna) were subjected to database searches and compared to genome sequences of Francisella strains (accession nos AM233362, CP000803, CP000437, AJ749949, CP000439, AM286280 and CP000608).

Primers used in the multiplex PCR were constructed based on comparative genomic fingerprinting and information from the literature. By means of RAPD-PCR, sequence fragments potentially suitable for the design of specific primers were identified and sequenced for strains of $F$. piscicida (RAPD12 band of $201 \mathrm{bp}$ ) and F. philomiragia (RAPD6 band of $1259 \mathrm{bp}$ ) and FhSp1 ${ }^{\mathrm{T}}$ (RAPD13 band of $770 \mathrm{bp}$ ) (not shown). For F. tularensis subsp. mediasiatica, a specific primer pair was designed using a variable region that was detected after comparison of larger sequence regions of the $F$. tularensis subsp. mediasiatica genome sequence with other accessible Francisella genome sequences from the databases. The region of difference RD1 described by Broekhuijsen et al. (2003) provided a 
primer pair that resulted in specific products for $F$. tularensis subsp. tularensis and F. tularensis subsp. holarctica, including biovar japonica [the reverse primer was taken from Broekhuijsen et al. (2003) and the forward primer was redesigned], and was also used to design a primer pair specific for $F$. novicida (for amplicon sizes, see Table 3). The primer pair RD6_f/r (Molins-Schneekloth et al., 2007) allowed differentiation between F. tularensis subsp. tularensis A.I and A.II by lack of the F. tularensis species-specific band of 369 bp in ATCC $6223^{\mathrm{T}}$ (A.II).

The primer pairs were tested in individual PCRs (results not shown) and then integrated into one multiplex-PCR assay. The $25 \mu \mathrm{l}$ reaction mixture consisted of $5 \mu \mathrm{l} 5 \times$ buffer, $2.5 \mu \mathrm{l} \mathrm{MgCl}_{2}, 0.5 \mu \mathrm{l}$ dNTPs, $0.2 \mu \mathrm{l}$ each of primers RD1_new_f, RD1_r, F_nov_f and F_nov_r, $0.1 \mu$ l each of primers RD6_f, RD6_r, F_pisc_f, F_pisc_r, F_philo_f, F_philo_r, F_62_f, F_62_r, F_med_f and F_med_r, $0.12 \mu \mathrm{l}$ Promega GoTaq polymerase and $0.5 \mu$ template DNA. Reactions were performed in an Eppendorf Mastercycler using an initial $5 \mathrm{~min}$ denaturation step at $95{ }^{\circ} \mathrm{C}$ followed by 35 cycles of $1 \mathrm{~min}$ at $95{ }^{\circ} \mathrm{C}, 1 \mathrm{~min}$ at $60{ }^{\circ} \mathrm{C}$ and $1 \mathrm{~min} 30 \mathrm{~s}$ at $72{ }^{\circ} \mathrm{C}$ and a final extension step of $5 \mathrm{~min}$ at $72{ }^{\circ} \mathrm{C}$. The products were separated in a $1.5 \%$ agarose gel as described above, stained with ethidium bromide and visualized with UV light. Applying the developed multiplex PCR, all test strains could be correctly identified (Table 3 and Fig. 3). The assay uses 14 primers

Table 3. Francisella strains examined in this study and their multiplex PCR profiles

\begin{tabular}{|c|c|c|}
\hline Strain & Taxon as received & Multiplex PCR profile (bp) \\
\hline \multicolumn{3}{|l|}{ F. tularensis subsp. holarctica } \\
\hline $\mathrm{F} 124^{\mathrm{T}}=\mathrm{GIEM} 503^{\mathrm{T}}$ & F. tularensis subsp. holarctica & 369,629 \\
\hline $\mathrm{F} 4$ & F. tularensis subsp. holarctica BVII & 369,629 \\
\hline F7 & F. tularensis subsp. holarctica BVII & 369,629 \\
\hline F9 & F. tularensis subsp. holarctica BVII & 369,629 \\
\hline F12 & F. tularensis subsp. holarctica BVII & 369,629 \\
\hline F13 & F. tularensis subsp. holarctica BVII & 369,629 \\
\hline F17 & F. tularensis subsp. holarctica BVII & 369,629 \\
\hline F19 & F. tularensis subsp. holarctica BVII & 369,629 \\
\hline F33 & F. tularensis subsp. holarctica BVII & 369,629 \\
\hline F57 & F. tularensis subsp. holarctica & 369,629 \\
\hline F101 & F. tularensis subsp. holarctica & 369,629 \\
\hline F49 =ATCC 29684 & F. tularensis subsp. holarctica LVS & 369,629 \\
\hline $\mathrm{F} 119=\mathrm{FSC} 021$ & F. tularensis subsp. holarctica bv. japonica & 369,840 \\
\hline $\mathrm{F} 120=\mathrm{FSC} 022$ & F. tularensis subsp. holarctica bv. japonica & 369,840 \\
\hline \multicolumn{3}{|l|}{ F. tularensis subsp. tularensis } \\
\hline $\mathrm{F} 66^{\mathrm{T}}=$ ATCC $6223^{\mathrm{T}}=$ GIEM Schu $^{\mathrm{T}}$ & F. tularensis subsp. tularensis, avirulent; A.II & 1325 \\
\hline FSC237 =SCHU S4 & F. tularensis subsp. tularensis; A.I & 369,1325 \\
\hline \multicolumn{3}{|l|}{ F. tularensis subsp. mediasiatica } \\
\hline $\mathrm{F} 63^{\mathrm{T}}=\mathrm{GIEM} 43^{\mathrm{T}}$ & F. tularensis subsp. mediasiatica & 369,1132 \\
\hline F65 & F. tularensis subsp. mediasiatica & 369,1132 \\
\hline \multicolumn{3}{|l|}{ F. tularensis subsp. novicida } \\
\hline \multicolumn{3}{|l|}{ F. philomiragia } \\
\hline $\mathrm{F} 51^{\mathrm{T}}=\mathrm{ATCC} 25015^{\mathrm{T}}$ & F. philomiragia & 962 \\
\hline F50 =ATCC 25017 & F. philomiragia & 962 \\
\hline \multicolumn{3}{|l|}{ F. piscicida } \\
\hline $\mathrm{F} 165^{\mathrm{T}}=\mathrm{DSM} 18777^{\mathrm{T}}$ & F. piscicida & 172 \\
\hline
\end{tabular}




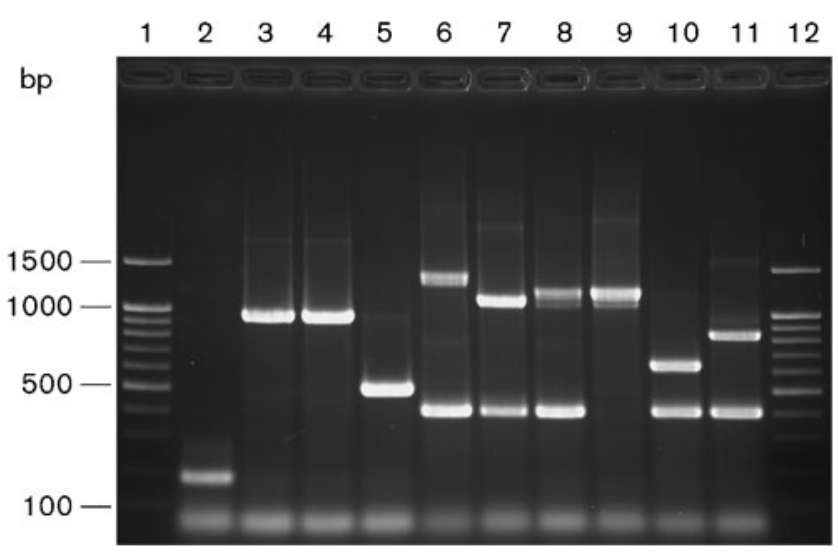

Fig. 3. Multiplex PCR results. Lanes: 1 and $12,100 \mathrm{bp}$ and $1.5 \mathrm{~kb}$ markers; 2, F. piscicida DSM $18777^{\top}$; 3, F. philomiragia ATCC 25017; 4, F. philomiragia ATCC $25015^{\top} ; 5$, F. hispaniensis sp. nov. FhSp1 $1^{\mathrm{T}}$; 6, F. novicida ATCC $15482^{\mathrm{T}} ; 7$, F. tularensis subsp. mediasiatica GIEM543 ${ }^{\top} ; 8$, F. tularensis subsp. tularensis SCHU S4 (A.I); 9, F. tularensis subsp. tularensis ATCC $6223^{\top}$ (A.II); 10, F. tularensis subsp. holarctica GIEM503 ${ }^{\top} ; 11, F$. tularensis subsp. holarctica bv. japonica F119. Aliquots of $5 \mu \mathrm{l}$ PCR product were loaded onto the $1.5 \%$ agarose gel and visualized after staining with ethidium bromide.

and allows the differentiation of all Francisella species and subspecies including biovar japonica of F. tularensis subsp. holarctica and biovars A.I and A.II of F. tularensis subsp. tularensis.

Strain $\mathrm{FhSp}^{\mathrm{T}}$ was shown to be distant from the other established Francisella species by sequence analyses of different housekeeping genes (Nübel et al., 2006) as well as in RAPD-PCR and the developed multiplex PCR. Hence, these results indicate that this strain is not a representative of F. novicida or of any other recognized Francisella species, but a representative of a novel species of the genus Francisella.

In order to support the rank of a separate species, DNA reassociation experiments were carried out comparing FhSp $1^{\mathrm{T}}$ with the type strains of two F. tularensis subspecies, F. novicida ATCC $15482^{\mathrm{T}}$, F. philomiragia ATCC $25015^{\mathrm{T}}$ and F. piscicida DSM $18777^{\mathrm{T}}$. DNA-DNA hybridization experiments were carried out according to Ziemke et al. (1998). Nick translation was done with $2 \mu \mathrm{g}$ DNA for $90 \mathrm{~min}$ at $15{ }^{\circ} \mathrm{C}$. High-molecular-mass DNA was extracted and purified according to Pitcher et al. (1989). DNA concentrations were estimated chemically according to Richards (1974). The results are means from at least six hybridizations. In hybridization experiments, strain FhSp $1^{\mathrm{T}}$ exhibited the following levels of reassociation: $52 \% \quad(9.7 \%$ SD), reciprocal $54 \% \quad(4.7 \%$ SD), with $F$. novicida ATCC $15482^{\mathrm{T}} ; 61 \%$ (8.4\% SD), reciprocal $35 \%$ (3\% SD), with F. tularensis subsp. mediasiatica GIEM543 ${ }^{\mathrm{T}}$;

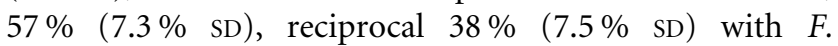

tularensis subsp. holarctica GIEM503 ${ }^{\mathrm{T}} ; 39 \%(7.7 \%$ SD), reciprocal $43 \%(5.9 \% \mathrm{SD})$, with $F$. philomiragia ATCC $25015^{\mathrm{T}}$; and $47 \%(3.4 \% \mathrm{SD})$, reciprocal $28 \%(6.2 \% \mathrm{SD})$, with F. piscicida DSM $18777^{\mathrm{T}}$. DNA-DNA hybridization was not carried out successfully with the type strain of $F$. tularensis subsp. tularensis because DNA from repeated purifications of differently grown biomass was heavily fragmented. However, hybridizations between all other subspecies of $F$. tularensis and F. novicida have shown that the subspecies of $F$. tularensis and $F$. novicida exhibit reassociation values higher than $70 \%$, demonstrating that they belong to a single species (Hollis et al., 1989). Hence, the strains of $F$. tularensis employed in our hybridization experiments are useful for reference and demonstrate unambiguously that $\mathrm{FhSp}^{\mathrm{T}}$ can be considered as a representative of an as-yet undescribed species of Francisella.

The data presented here (polar lipids, quinone system, fatty acids) as well as molecular data from Nübel et al. (2006), Larsson et al. (2007) and Escudero et al. (2010) demonstrate that strain $\mathrm{FhSp}^{\mathrm{T}}$ is a member of the genus Francisella. Results from DNA-DNA hybridization and unique physiological traits show that $\mathrm{FhSp}^{\mathrm{T}}$ is a representative of a novel Francisella species. Therefore, we propose a novel Francisella species, Francisella hispaniensis sp. nov., to accommodate strain $\mathrm{FhSp}^{\mathrm{T}}{ }^{\mathrm{T}}$.

The taxonomic status of $F$. novicida as one of four Francisella species has been questioned repeatedly. A range of different molecular data, including results of DNA-DNA hybridizations, has demonstrated a relatedness to $F$. tularensis at the species level. Sjöstedt (2005) discussed the matter in detail and proposed to reclassify $F$. novicida (Larson et al. 1955) Olsufiev et al. 1959 as ' $F$. tularensis subsp. novicida'. This new combination is used in several papers; however, this combination has not been validly published by publication in the International Journal of Systematic and Evolutionary Microbiology or by inclusion in a Validation List to satisfy Rule 27 of the Bacteriological Code and, hence, has no standing in nomenclature.

Here, we propose to reclassify $F$. novicida as a subspecies of F. tularensis, Francisella tularensis subsp. novicida comb. nov., and therefore give the already widely adopted classification a formal basis. Furthermore, we provide an emended description of the genus Francisella.

\section{Emended description of the genus Francisella Dorofe'ev 1947}

Francisella (Fran.ci.sel'la. N.L. dim. ending -ella; N.L. fem. n. Francisella named after Edward Francis, American bacteriologist, who extensively studied the aetiological agent and pathogenesis of tularaemia and is credited with naming the disease).

In addition to the description of the genus provided by Sjöstedt (2005), species of the genus are characterized by a complex polar lipid profile consisting of the major 
components diphosphatidylglycerol and phosphatidylethanolamine, moderate to major quantities of phosphatidylcholine and minor amounts of phosphatidylglycerol, three unidentified phospholipids, an aminolipid, two aminophosphoglycolipids and two aminophospholipids. Additional lipids may be present. The quinone system is ubiquinone Q-8. The type species is Francisella tularensis.

\section{Description of Francisella hispaniensis sp. nov.}

Francisella hispaniensis (his.pa.ni.en'sis. L. fem. adj. hispaniensis from Hispania, the Latin name for Spain, the country where the type strain was isolated).

Cells are pleomorphic or coccoid rods (approx. $0.5 \times 1.5 \mu \mathrm{m})$. Gram-negative, oxidase-positive and showing weak catalase activity. Good growth occurs on HCA and Columbia blood agar at $20-42{ }^{\circ} \mathrm{C}$ with an optimum at $37{ }^{\circ} \mathrm{C}$. Forms distinct, mucoid, pale-white to grey colonies within $24 \mathrm{~h}$ with a diameter of approx. 1-2 mm on HCA. Resistant to meropenem, amoxicillin plus clavulanic acid, ampicillin and aztreonam; susceptible to chloramphenicol, tetracycline, doxycycline, gentamicin, tobramycin, streptomycin, nalidixic acid, ciprofloxacin, levofloxacin, erythromycin and rifampicin. Does not produce indole or $\mathrm{H}_{2} \mathrm{~S}$. Negative in the Voges-Proskauer test, nitrate reduction and growth on triple-sugar iron agar. Gelatin and aesculin are not hydrolysed. Negative for arginine dihydrolase, ornithine decarboxylase, lysine decarboxylase, urease and $\beta$-galactosidase. The quinone system consists of Q-8 and traces of Q-9. Predominant polar lipids are phosphatidylethanolamine and phosphatidylcholine, as well as an unknown $F$. tularensis-specific aminophospholipid (APL4). Other polar lipids are diphosphatidylglycerol, phosphatidylglycerol, unknown phospholipids (PL1-3), an unknown lipid (L) and some unknown aminophosphoglycolipids (APGL1-2), aminophospholipids (APL1-2) and aminolipids (AL2). The fatty acid profile is mainly composed of the major compounds $\mathrm{C}_{10: 0}, \mathrm{C}_{14: 0}, \mathrm{C}_{16: 0}$ and the hydroxy acid $\mathrm{C}_{18: 0} 3-\mathrm{OH}$, as well as minor amounts of $\mathrm{C}_{18: 1} \omega 9 c, \mathrm{C}_{18: 0}, \mathrm{C}_{16: 0} 3-\mathrm{OH}$ and $\mathrm{C}_{10: 0}$ 2-OH. Results of biochemical tests are indicated in Table 2.

The type strain, $\mathrm{FhSp}^{\mathrm{T}}\left(=\mathrm{FnSp} 1^{\mathrm{T}}=\mathrm{FSC}^{\mathrm{T}} 44^{\mathrm{T}}=\mathrm{F} 62^{\mathrm{T}}\right.$ $=$ DSM $22475^{\mathrm{T}}=$ CCUG $58020^{\mathrm{T}}$ ), was isolated in Spain in 2003 from blood of a patient suffering severe septicaemia secondary to acute obstructive pyelonephritis (Escudero et al., 2010).

\section{Description of Francisella tularensis subsp. novicida comb. nov.}

Francisella tularensis subsp. novicida (no.vi.ci'da. L. adj. novus new; L. suff. -cida from L. v. caedo to cut, kill; N.L. n. novicida new killer).

Basonym: Francisella novicida (Larson et al. 1955) Olsufiev et al. 1959.
Other synonym: 'Pasteurella novicida' Larson et al. 1955.

The species shares the characteristics listed in the emended genus description. Further characteristics were summarized by Larson et al. (1955) and Sjöstedt (2005). Biochemical characteristics determined with the Biolog GN2 MicroPlate are shown in Table 2.

The type strain, ATCC $15482^{\mathrm{T}}=$ CCUG $33449^{\mathrm{T}}=$ CIP $56.12^{\mathrm{T}}$, was isolated from a water sample from Ogden Bay, Utah, USA, in 1951 (Larson et al., 1955).

\section{Acknowledgements}

This study was supported by a Contract-Research Project of the German Ministry of Defence (grant no. M-SAB1-5-A005) and grant EM03/06 from Instituto de Salud Carlos III, Spain.

\section{References}

Altenburger, P., Kämpfer, P., Makristathis, A., Lubitz, W. \& Busse, H.-J. (1996). Classification of bacteria isolated from a medieval wall painting. J Biotechnol 47, 39-52.

Broekhuijsen, M., Larsson, P., Johansson, A., Byström, M., Eriksson, U., Larsson, E., Prior, R. G., Sjöstedt, A., Titball, R. W. \& Forsman, M. (2003). Genome-wide DNA microarray analysis of Francisella tularensis strains demonstrates extensive genetic conservation within the species but identifies regions that are unique to the highly virulent F. tularensis subsp. tularensis. J Clin Microbiol 41, 2924-2931.

Escudero, R., Elía, M., Sáez-Nieto, J. A., Herrera, L., Galán, J. A., Ruiz, M., Menéndez, V., Royo, G. \& Anda, P. (2003). Preliminary characterization of a human isolate of Francisella novicida. In Abstracts of the 4th International Conference on Tularemia, 15-18 September 2003, Bath, UK, p. 30.

Escudero, R., Toledo, A., Gil, H., Kovácsová, K., Rodriguez-Vargas, M., Jado, I., García-Amil, C., Lobo, B. \& Bhide, M. (2008). Molecular method for discrimination between Francisella tularensis and Francisella-like endosymbionts. J Clin Microbiol 46, 3139-3143.

Escudero, R., Elía, M., Sáez-Nieto, J. A., Menéndez, V., Toledo, A., Royo, G., Rodríguez-Vargas, M., Whipp, M. J., Gil, H. \& other authors (2010). A possible novel Francisella genomic species isolated from blood and urine of a patient with severe illness. Clin Microbiol Infect 16, 1026-1030.

Forsman, M., Sandstrom, G. \& Sjöstedt, A. (1994). Analysis of $16 \mathrm{~S}$ ribosomal DNA sequences of Francisella strains and utilization for determination of the phylogeny of the genus and for identification of strains by PCR. Int J Syst Bacteriol 44, 38-46.

Gao, B., Mohan, R. \& Gupta, R. S. (2009). Phylogenomics and protein signatures elucidating the evolutionary relationships among the Gammaproteobacteria. Int J Syst Evol Microbiol 59, 234-247.

Hollis, D. G., Weaver, R. E., Steigerwalt, A. G., Wenger, J. D., Moss, C. W. \& Brenner, D. J. (1989). Francisella philomiragia comb. nov. (formerly Yersinia philomiragia) and Francisella tularensis biogroup novicida (formerly Francisella novicida) associated with human disease. J Clin Microbiol 27, 1601-1608.

Jantzen, E., Berdal, B. P. \& Omland, T. (1979). Cellular fatty acid composition of Francisella tularensis. J Clin Microbiol 10, 928-930.

Johansson, A., Ibrahim, A., Göransson, I., Eriksson, U., Gurycova, D., Clarridge, J. E. \& Sjöstedt, A. (2000). Evaluation of PCR-based methods for discrimination of Francisella species and subspecies and development of a specific PCR that distinguishes the two major subspecies of Francisella tularensis. J Clin Microbiol 38, 4180-4185. 
Kämpfer, P. \& Kroppenstedt, R. M. (1996). Numerical analysis of fatty acid patterns of coryneform bacteria and related taxa. Can J Microbiol 42, 989-1005.

Kugeler, K. J., Mead, P. S., McGowan, K. L., Burnham, J. M., Hogarty, M. D., Ruchelli, E., Pollard, K., Husband, B., Conley, C. \& other authors (2008). Isolation and characterization of a novel Francisella sp. from human cerebrospinal fluid and blood. J Clin Microbiol 46, 2428-2431.

Lane, D. J. (1991). 16S/23S rRNA sequencing. In Nucleic Acid Techniques in Bacterial Systematics, pp. 115-175. Edited by E. Stackebrandt \& M. Goodfellow. Chichester: Wiley.

Larson, C. L., Wicht, W. \& Jellison, W. L. (1955). A new organism resembling $P$. tularensis isolated from water. Public Health Rep 70, 253-258.

Larsson, P., Svensson, K., Karlsson, L., Guala, D., Granberg, M., Forsman, M. \& Johansson, A. (2007). Canonical insertion-deletion markers for rapid DNA typing of Francisella tularensis. Emerg Infect Dis 13, 1725-1732.

Lau, K. W. K., Ren, J., Fung, M.-C., Woo, P. C. Y., Yuen, K.-Y., Chan, K. K. M., Qian, P.-Y., Wong, P.-K. \& Wu, M. (2007). Fangia hongkongensis gen. nov., sp. nov., a novel gammaproteobacterium of the order Thiotrichales isolated from coastal seawater of Hong Kong. Int J Syst Evol Microbiol 57, 2665-2669.

Leelaporn, A., Yongyod, S., Limsrivanichakorn, S., Yungyuen, T. \& Kiratisin, P. (2008). Francisella novicida bacteremia, Thailand. Emerg Infect Dis 14, 1935-1937.

McCoy, G. W. \& Chapin, C. W. (1912). Further observations on a plague-like disease of rodents with a preliminary note on the causative agent, Bacterium tularense. J Infect Dis 10, 61-72.

Mikalsen, J., Olsen, A. B., Tengs, T. \& Colquhoun, D. J. (2007). Francisella philomiragia subsp. noatunensis subsp. nov., isolated from farmed Atlantic cod (Gadus morhua L.). Int J Syst Evol Microbiol 57, 1960-1965.

Molins-Schneekloth, C. R., Belisle, J. T. \& Petersen, J. M. (2007). Genomic markers for differentiation of Francisella tularensis subsp. tularensis A.I and A.II. Appl Environ Microbiol 74, 336-341.

Muyzer, G., de Waal, E. C. \& Uitterlinden, A. G. (1993). Profiling of complex microbial populations by denaturing gradient gel electrophoresis analysis of polymerase chain reaction-amplified genes coding for 16S rRNA. Appl Environ Microbiol 59, 695-700.

Nübel, U., Reissbrodt, R., Weller, A., Grunow, R., PorschÖzcürümez, M., Tomaso, H., Hofer, E., Splettstoesser, W., Finke, E.-J. \& other authors (2006). Population structure of Francisella tularensis. J Bacteriol 188, 5319-5324.

Olsufiev, N. G., Emelyanova, O. S. \& Dunaeva, T. N. (1959). Comparative studies of strains of $B$. tularense in the Old and New World and their taxonomy. J Hyg Epidemiol Microbiol Immunol 3, 138-149.
Olsufjev, N. G. \& Meshcheryakova, I. S. (1983). Subspecific taxonomy of Francisella tularensis McCoy and Chapin 1912. Int J Syst Bacteriol 33, 872-874.

Ottem, K. F., Nylund, A., Karlsbakk, E., Friis-Møller, A., Krossoy, B. \& Knappskog, D. (2007). New species in the genus Francisella (Gammaproteobacteria; Francisellaceae); Francisella piscicida sp. nov. isolated from cod (Gadus morhua). Arch Microbiol 188, 547-550.

Ottem, K. F., Nylund, A., Karlsbakk, E., Friis-Møller, A. \& Kamaishi, T. (2009). Elevation of Francisella philomiragia subsp. noatunensis Mikalsen et al. (2007) to Francisella noatunensis comb. nov. [syn. Francisella piscicida Ottem et al. (2008) syn. nov.] and characterization of Francisella noatunensis subsp. orientalis subsp. nov., two important fish pathogens. J Appl Microbiol 106, 1231-1243.

Pearson, W. R. \& Lipman, D. J. (1988). Improved tools for biological sequence comparison. Proc Natl Acad Sci U S A 85, 2444-2448.

Pitcher, D. G., Saunders, N. A. \& Owen, R. J. (1989). Rapid extraction of bacterial genomic DNA with guanidium thiocyanate. Lett Appl Microbiol 8, 151-156.

Richards, G. M. (1974). Modifications of the diphenylamine reaction giving increased sensitivity and simplicity in the estimation of DNA. Anal Biochem 57, 369-376.

Scholz, H. C., Tomaso, H., Al Dahouk, S., Witte, A., Schloter, M., Kämpfer, P., Falsen, E. \& Neubauer, H. (2006). Genotyping of Ochrobactrum anthropi by recA-based comparative sequence, PCRRFLP, and 16S rRNA gene analysis. FEMS Microbiol Lett 257, 7-16.

Sjöstedt, A. B. (2005). Genus I. Francisella Dorofe'ev 1947, $176^{\mathrm{AL}}$. In Bergey's Manual of Systematic Bacteriology, 2nd edn, vol. 2, part B, pp. 200-210. Edited by D. J. Brenner, N. R. Krieg, J. T. Staley \& G. M. Garrity. New York: Springer.

Stolz, A., Busse, H.-J. \& Kämpfer, P. (2007). Pseudomonas knackmussii sp. nov. Int J Syst Evol Microbiol 57, 572-576.

Tamura, K., Dudley, J., Nei, M. \& Kumar, S. (2007). MEGA4: molecular evolutionary genetics analysis (MEGA) software version 4.0. Mol Biol Evol 24, 1596-1599.

Thompson, J. D., Gibson, T. J., Plewniak, F., Jeanmougin, F. \& Higgins, D. G. (1997). The CLUSTAL_X windows interface: flexible strategies for multiple sequence alignment aided by quality analysis tools. Nucleic Acids Res 25, 4876-4882.

Tindall, B. J. (1990a). A comparative study of the lipid composition of Halobacterium saccharovorum from various sources. Syst Appl Microbiol 13, 128-130.

Tindall, B. J. (1990b). Lipid composition of Halobacterium lacusprofundi. FEMS Microbiol Lett 66, 199-202.

Wieser, M. \& Busse, H.-J. (2000). Rapid identification of Staphylococcus epidermidis. Int J Syst Evol Microbiol 50, 1087-1093.

Ziemke, F., Höfle, M. G., Lalucat, J. \& Rosselló-Mora, R. (1998). Reclassification of Shewanella putrefaciens Owen's genomic group II as Shewanella baltica sp. nov. Int J Syst Bacteriol 48, 179-186. 